\title{
An Attempt to Discover Antenatal Etiological Factors for Cerebral Palsy: What does 3D and 4D Ultrasonography Add?
}

\author{
${ }^{1}$ Asim Kurjak, ${ }^{1}$ Milan Stanojevic, ${ }^{1}$ Ingrid Marton, ${ }^{2}$ Mislav Herman, ${ }^{3}$ Guillermo Azumendi \\ ${ }^{1}$ Department of Obstetrics and Gynecology, Medical School, University of Zagreb, Sveti Duh Hospital, Zagreb, Croatia \\ ${ }^{2}$ Department of Obstetrics and Gynecology, Medical School, University of Zagreb, Petrova Hospital, Zagreb, Croatia \\ ${ }^{3}$ Ecographia Centro Gutenberg, Malaga, Spain
}

Correspondence: Prof Asim Kurjak

Department of Obstetrics and Gynecology, Medical School, University of Zagreb

Sveti Duh Hospital, Sveti Duh 64 Zagreb, Croatia

Tel. : + 38513712319 , Fax: + 38513745534 , e-mail : asim.kurjak@zg.t-com.hr

\begin{abstract}
Cerebral palsy (CP) is a nonprogressive condition affecting developing fetal or infant brain resulting in disorders of movement and posture which are sometimes accompanied by disturbances of cognition, sensation, perception, behavior and seizures. The incidence of $\mathrm{CP}$ being 2 to 2.5 per 1000 live births did not considerably change in the last decades. Improvement of perinatal care did not result in the decreasing prevalence of CP. Consensus Statement of International Cerebral Palsy Task Force and its modification presented the essential criteria to define an acute intrapartum event sufficient to cause CP. These criteria were not helpful in allocating the time of brain injury, proving that etiology of $\mathrm{CP}$ is difficult to investigate. Better markers of acute intrapartum injury should be defined, although much evidence exists that most causes of CP are prenatal. Advances in 3D and 4D ultrasound (US) give opportunities to investigate fetal morphology and behavior. By 4D US, head, body and limb movements can be visualized simultaneously. The earliest phase of development can be studied in detail, making 4D superior compared to 2D. Is applicable neurological test for fetus available? This question is complicated, because even postnatally several neurological methods of evaluation exist, while hardly accessible fetus has less mature brain. Inexistence of reliable neurobehavioral assessment method for the fetuses is discouraging. The scientific community should intensify efforts in finding out simple, clinically applicable, and reproducible fetal neurological test(s), with fair sensitivity and specificity.
\end{abstract}

Key words: Cerebral palsy, fetal behavior, 4D/3D ultrasonography, neurological assessment.

Learning objectives

- To introduce a basic knowledge of cerebral palsy (CP)

- To inform about obstetrical causes of CP

- To give an overview of the methods for the neurological assessment of the fetus by 4D ultrasonography.

\section{INTRODUCTION}

Cerebral palsy (CP) is a nonprogressive condition affecting developing fetal or infant brain resulting in different disorders of movement and posture which are sometimes accompanied by disturbances of cognition, sensation, perception, behavior and seizures. ${ }^{1-4}$ It is defined as an "umbrella term covering a group of nonprogressive, but often changing motor impairment syndromes secondary to lesions or anomalies of the brain arising in the early stages of its development". ${ }^{1-4}$ Together with autism and mental retardation, it is one of the three most common life long developmental disabilities. ${ }^{3}$

\section{IMPORTANT FACTS ABOUT CEREBRAL PALSY: OBSTETRICAL POINT OF VIEW}

The worldwide incidence of CP being 2 to 2.5 per 1000 live births makes it common condition, which incidence, as shown in the Figure 1, did not considerably change in the last thirty years. ${ }^{5-7}$ Improvement of obstetrical and neonatal care did not result in the decreasing prevalence rate of CP. On the contrary, the incidence and severity of CP increased due to a better survival rate of very immature and tiny premature infants with significant morbidity and increased number of risk factors. ${ }^{6,8}$ Little, who introduced the term cerebral palsy, advanced the hypothesis that the main causes of the condition were prematurity, asphyxia neonatorum and birth trauma. There is still widespread believe that adverse events in labor are responsible for development of $\mathrm{CP}$ and even more that those events are potentially preventable. ${ }^{9}$ According to recent studies, most of the risk factors connected with development of CP are 
prenatal, while delivery and intrapartum risk factors are considered to have minor role, as shown in the Figure $2 .{ }^{10}$ As $\mathrm{CP}$ became the most important part of global childbirth litigation industry providing to the crisis of obstetrical care especially in developed countries, efforts have been made in order to better define an acute intrapartum events sufficient to cause CP. ${ }^{9,11,12}$ According to the Consensus Statement of International Cerebral Palsy Task Force published in 1999, and its modification published in 2003, the essential criteria to define an acute intrapartum event sufficient to cause $\mathrm{CP}$ are given in the Table $1 .{ }^{12,13}$ According to some publications, the most serious critics to the proposed criteria is that information about essential criteria are frequently missing from the medical records of children who were retrospectively investigated. ${ }^{9}$ In another investigation none of the cases of $\mathrm{CP}$ born at term met all of the criteria for severe acute intrapartum hypoxia as a possible cause of CP. ${ }^{14}$ In most cases, criteria clearly ruled out acute intrapartum hypoxia. ${ }^{14}$ Nearly, $9 \%$ of the cases met the criteria for a severe metabolic acidosis at birth, and fewer than $20 \%$ of cases at term had early imaging evidence of an acute nonfocal cerebral abnormality. ${ }^{14}$ On the other hand, many children with cerebral palsy have had one or more of the clinical signs which are widely assumed to reflect "fetal distress", but which may not represent acute intrapartum hypoxia. ${ }^{9}$ The mentioned criteria were not helpful in allocating the time of brain injury, proving that etiology of CP is complex and difficult to investigate. ${ }^{9,14}$ There is a need for better markers of acute intrapartum injury, although there is much evidence that most adverse events causing CP happen prenatally. ${ }^{9,14}$ Major pathologies associated with $\mathrm{CP}$ are listed in the Table $2 .{ }^{14}$

Table 1: Criteria to define an acute intrapartum hypoxic event ${ }^{13}$

\section{Essential criteria}

1. Evidence of a metabolic acidosis in intrapartum fetal, umbilical arterial cord, or very early neonatal blood samples $(\mathrm{pH}<7.00$ and base deficit $>12 \mathrm{mmol} / \mathrm{l}$ ).

2. Early onset of severe or moderate neonatal encephalopathy in infants born at 34 or more weeks of gestation.

3. Cerebral palsy of the spastic quadriplegic or dyskinetic type.

4. Exclusion of other identifiable etiologies, such as trauma, coagulation disorders, infectious conditions, or genetic disorders.

Criteria that together suggest an intrapartum timing (within close proximity to labor and delivery, for example, 0-48 hours) but by themselves are nonspecific for an asphyxial insult.

1. A sentinel (signal) hypoxic event occurring immediately before or during labor.

2. A sudden and sustained fetal bradycardia or the absence of fetal heart rate variability in the presence of persistent late or persistent variable decelerations, usually after a hypoxic sentinel event when the pattern was previously normal.

3. Apgar scores of 0-3 beyond 5 minutes.

4. Onset of multisystem involvement within 72 hours of birth.

5. Early imaging evidence of acute nonfocal cerebral abnormality.

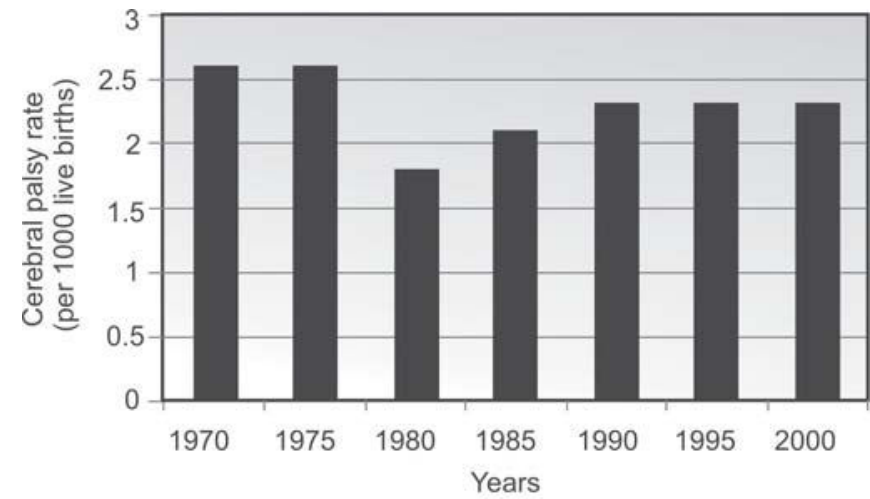

Fig. 1: Cerebral palsy rates per 1000 live births (1970-2000) ${ }^{7}$

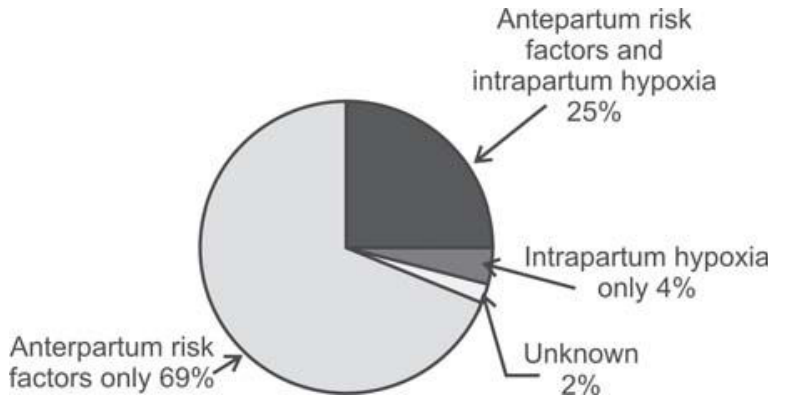

Fig. 2: Distribution of risk factors for newborn encephalopathy ${ }^{10}$

Table 2: Major pathologies associated with cerebral palsy ${ }^{14}$

- Prematurity

- Antepartum hemorrhage

- Complications of multiple pregnancy

- Genetic disorders

- Intrauerine infection; for example, chorioamnionitis, funisitis, villitis, cytomegalovirus, toxoplasmosis

- Intrapartum fever

- Intrauterine growth restriction

- Maternal and fetal coagulopathies

- Multiple congenital anomalies

- Maternal disease; for example, hypothyroidism, diabetes, drug abuse, severe pre-eclampsia, viral illness

- Placental pathology; for example, major infarction, thrombotic vasculopathy

- Tight nuchal cord

- Childhood causes

- Other causes; for example, fetal hemorrhage, rhesus disease.

\section{THE DIAGNOSIS OF CP FROM OBSTETRICAL POINT OF VIEW}

The detection of $\mathrm{CP}$ is retrospective and it is exceptionally made before the age of 6 months in only most severely affected infants, and the specificity of the diagnosis will improve as the child ages and the nature of the disability evolves. ${ }^{15}$ Cerebral palsy does not result from a single event but rather there is a sequence 
of interdependent adverse events providing to the condition. ${ }^{16}$ This time frame of evolving adverse events is something which should be taken into account when thinking about the possibility of development of CP in infants. ${ }^{15,16}$ The understanding of the profile of a child's disability across multiple domains is an ongoing process necessary for appropriate treatment and future planning. ${ }^{15}$ This theoretical statement is sometimes very difficult to be practically implemented. Possible antenatal causes of neurological impairment are listed in Table $3 .^{12}$ An attempt to make early diagnosis of CP should be followed with factors related to pathogenesis, impairment and functional limitations in every patient. ${ }^{15}$ In order to identify pathogenesis of the process, neuroimaging methods should be used, among which cranial ultrasound, magnetic resonance imaging, magnetic resonance spectroscopy and diffusion weighted imaging are the most frequently used in very low birth weight premature infants and in term infants with encephalopathy. ${ }^{15}$ Impairment of organs or systems by clinical assessment of muscle tone, strength, control and voluntary movements for early detection of infants with the risk for $\mathrm{CP}$ has been frustrating, because $43 \%$ of 7 -year-old children with $\mathrm{CP}$ had a normal newborn neurologic examination. ${ }^{15,17}$ There is a possibility for the early simple neurological assessment of the term and preterm newborns with the aim to detect associated risks and anticipate long-term outcome of the infant, and to establish a possible causative link between pregnancy course and outcome. ${ }^{18} \mathrm{As} \mathrm{CP}$ is a disorder of movement and postural control resulting in functional limitations, their detection could be helpful in detection of early impairment. ${ }^{15}$ Clinical neurological assessment proposed and practiced by Amiel-Tison could be very helpful in the early detection of newborns at risk. $^{18}$

In the last thirty years objective assessment of videotaped general movements (GM) by Precht's method has been shown to be predictive of later $\mathrm{CP} .{ }^{19}$ The quality of general movements at 2 to 4 months postterm (so-called fidgety GM age) has been found to have highest predictive value in the detection of the infants at risk for CP development. ${ }^{20}$ It seems that assessment of the quality of GM is a window for early detection of children at high risk for developmental disorders. ${ }^{20}$ Method is very simple and it is based on the so-called Gestalt evaluation of GM complexity and variation. ${ }^{19,20}$ Assessment of GMs at 2 to 4 months postterm at so-called fidgety GM age has been found to have the highest predictive value for development of $\mathrm{CP}$, if abnormal. ${ }^{19,20}$

\section{IS PRENATAL DIAGNOSIS OF NEUROLOGICALLY DISABLED FETUS POSSIBLE?}

As the most factors providing to development of $\mathrm{CP}$ are prenatal, the eternal question is do we as obstetricians have means to detect fetuses at risk for development of $\mathrm{CP}$ early enough to
Table 3: Factors that suggest a cause of cerebral palsy other than acute intrapartum hypoxia ${ }^{12}$

- Umbilical arterial base deficit less than $12 \mathrm{mmol} / \mathrm{l}$ or $\mathrm{pH}$ greater than 7.00

- Infants with major or multiple congenital or metabolic abnormalities

- Central nervous system or systemic infection

- Early imaging evidence of long-standing neurological abnormalities; for example, ventriculomegaly, porencephaly, multicystic encephalomalacia

- Infants with signs of intrauterine growth restriction

- Reduced fetal heart rate variability from the onset of labor

- Microcephaly at birth (head circumference less than a third of the centile)

- Major antenatal placental abruption

- Extensive chorioamnionitis

- Congenital coagulation disorders in the child

- Presence of other major antenatal risk factors for cerebral palsy; for example, preterm birth at less than 34 weeks' gestation, multiple pregnancy, or autoimmune disease

- Presence of major postnatal risk factors for cerebral palsy; for example, postnatal encephalitis, prolonged hypotension, or hypoxia due to severe respiratory disease

- A sibling with cerebral palsy, especially of the same type.

protect them? So many difficult questions in only one sentence, hardly any answers. From the retrospective analysis of prevalence rates of $\mathrm{CP}$ in the last thirty years, we learned that there are no improvements in the obstetrical care which could enable early detection of CP. ${ }^{4-7}$ Although in the last 20 years, it has been observed a shift in focus in the search for the origins of developmental disabilities and dysfunction from the intrapartum to antenatal period, there was no substantial improvement in the prenatal detection of potentially disabled babies. ${ }^{21}$ The fact that no unified neurobehavioral assessment method of the fetuses currently exists is very discouraging and this fact should prompt the scientific community to intensify efforts in finding out such test(s) which should be simple, clinically applicable, and reproducible, with fair sensitivity and specificity. In order to achieve these goals, mentioned test should focus on gathering information that reveals neural continuity from fetus to newborn. ${ }^{22,23}$ This statement is relying on the basic principle of development of nervous system which is continuing from prenatal to postnatal life. Early developmental periods are dominated by proliferative and migratory processes, while later, neuronal differentiation and synaptogenesis are prevailing. ${ }^{22,23}$ Even harmful events during the first trimester can result in a variety of the CNS abnormalities, from severe neural tube defects to reduction of the number of neurons, which significantly reduces developmental potential. ${ }^{24}$ The fetal neurobehavioral assessment focuses on fetal heart rate monitoring, assessment of fetal activity, behavioral state and responsivity to stimulation or biophysical profile. ${ }^{21}$ Such assessment of the fetuses is still not sufficient to detect most of the fetuses at risk for development of $\mathrm{CP}$, with very important 
observation that prevalence rate of $\mathrm{CP}$ did not change substantially after introduction of all mentioned methods to clinical practice.

\section{INVESTIGATION OF FETAL BEHAVIOR BY 2D ULTRASONOGRAPHY}

The pioneer studies in the early 1980s of de Vries and colleagues have shown that the motor activity begins as early as the late embryonic period. ${ }^{19,25}$ They have studied quantity and the quality of fetal general movements (GM), observed their rapid increase during the first trimester, and visualized new motor patterns. ${ }^{19,25}$ Prechtl's school of fetal neurology described more than 20 years ago a large veriety of specific movement patterns emerging from 8 to 15 weeks of gestation, obtained by 2D sonography. ${ }^{19,26}$ Movements are similar to those observed in neonatal period. That observation is confirming not only the continuity from fetal to neonatal period but also the maturation from fetus to neonate (from fetal to neonatal). Therefore, the qualitative assessment of GMs became part of fetal and neonatal neurological evaluation. ${ }^{19,27}$ Since that time many new studies have been undertaken with precise description of different movement patterns, as well as their exact time of appearance during pregnancy. ${ }^{28,29}$ Many studies have shown that already in the early stage of pregnancy, embryonic and fetal motor activity appears as spontaneous patterned activity, rather than just a random motion. ${ }^{28-32}$ It has been observed that major movement patterns, usually develop and appear during the first trimester, explained by intensity of the motor development in this period of pregnancy. ${ }^{33-35}$ Fetal movements between 9 and 12 weeks of gestation are characterized by changes of position and posture, and between 13 and 16 weeks changes of position are seen, as well as flexion and extension of the limbs. From 17th to 20th gestational weeks, fetuses are making slow flexion and extension of the trunk, sometimes accompanied by the movement of a single limb. ${ }^{29}$ At that time fetuses perform isolated leg movements. ${ }^{30}$ Progressive organization of fetal motor activity and its integration with other parameters of fetal activity into the fetal behavioral status occurs during second and third trimesters. ${ }^{29,30,33}$

\section{D AND 4D ULTRASONOGRAPHY IN THE ASSESSMENT OF FETAL BEHAVIOR}

Recent advances in 3D and 4D ultrasonography provide us with new opportunities for the investigation of embryonic and fetal morphology and behavior. ${ }^{26,36}$ With 4D sonography, head and body movements, as well as all four limbs and extremities can be visualized simultaneously in three dimensions. ${ }^{37}$ Therefore, the earliest phase of anatomical and motor development can be observed and studied in detail, making $4 \mathrm{D}$ ultrasonography to be superior compared to $2 \mathrm{D} .^{38,39}$ Body movements were found by $4 \mathrm{D}$ at 7 weeks of pregnancy, and limb movements at 8 to 9 weeks, which is a week earlier than by $2 \mathrm{D} .{ }^{40}$ It is important to mention that some of the movement patterns cannot be observed through all the pregnancy like startles and stretches which are observed only in the first trimester disappearing with the progression of gestational age. 4D allows observing hand movements and subtle fetal movements, such as facial mimics and expressions, like sucking and swallowing which could be much better visualized during the second and the third trimesters. Majority of mentioned expressions could not be visualized by $2 \mathrm{D}$ ultrasound. ${ }^{41,42}$ 4D ultrasonography enables examination of fetal face with the awareness of a full range of facial expressions (Figs 3 and 4A and B), similar to those observed postnatally. In the study of Kurjak et al a reach repertoire of movements and facial expressions during the third trimester have been found and shown in the Table $4 .{ }^{43}$ Fetal motility is considered not only to reflect the developing nervous system but also involves functional and maturational properties of fetal hemodynamics and the muscular system. The introduction of 4D ultrasonography was a turning point in the assessment of fetal behavior by providing the capability of simultaneous spatial imaging of the entire fetus and its movements. ${ }^{33-35,41-51}$ As it was shown in our investigations, 4D has been used in establishing the standards of the quantity of GMs in different gestations, which is one step forward for the detection of fetal neurological test. Most types of movement patterns are present between 7 and 15 weeks of gestation. ${ }^{47}$ Once observed, the movements remain unchanged throughout the whole pregnancy. ${ }^{52}$ 4D US provided the possibility to study a full range of facial expressions including mouthing, grimacing, and eyelid movements (Figs $5 \mathrm{~A}$ to $\mathrm{C}){ }^{47-53}$ The definitions of types of analyzed movement patterns are presented in Tables 4 to 6 , following the studies by de Vries and Prechtl. ${ }^{52,54}$

We studied fetal behavior in all three trimesters of normal pregnancy and noted a tendency toward decreased frequency of observed facial expressions and movement patterns with

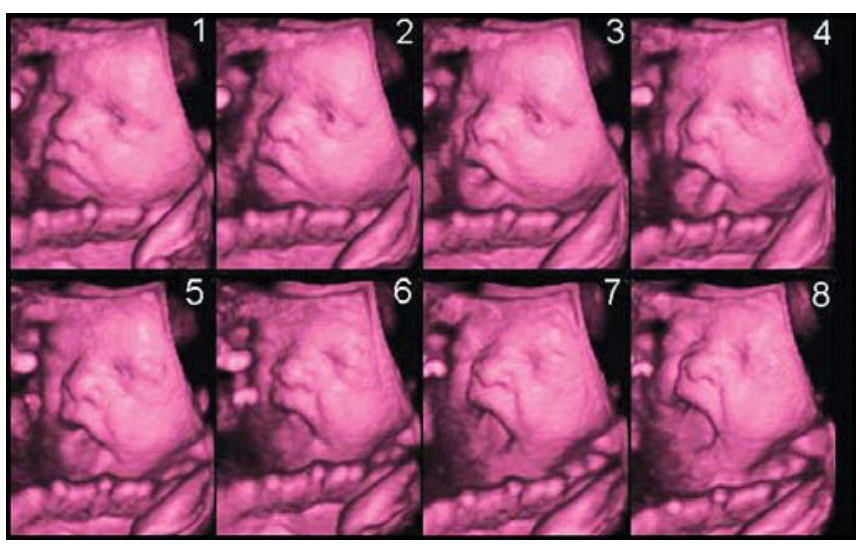

Fig. 3: 4D imaging sequences demonstrated isolated eye blinking parallel with tongue expulsion during third trimester of pregnancy 

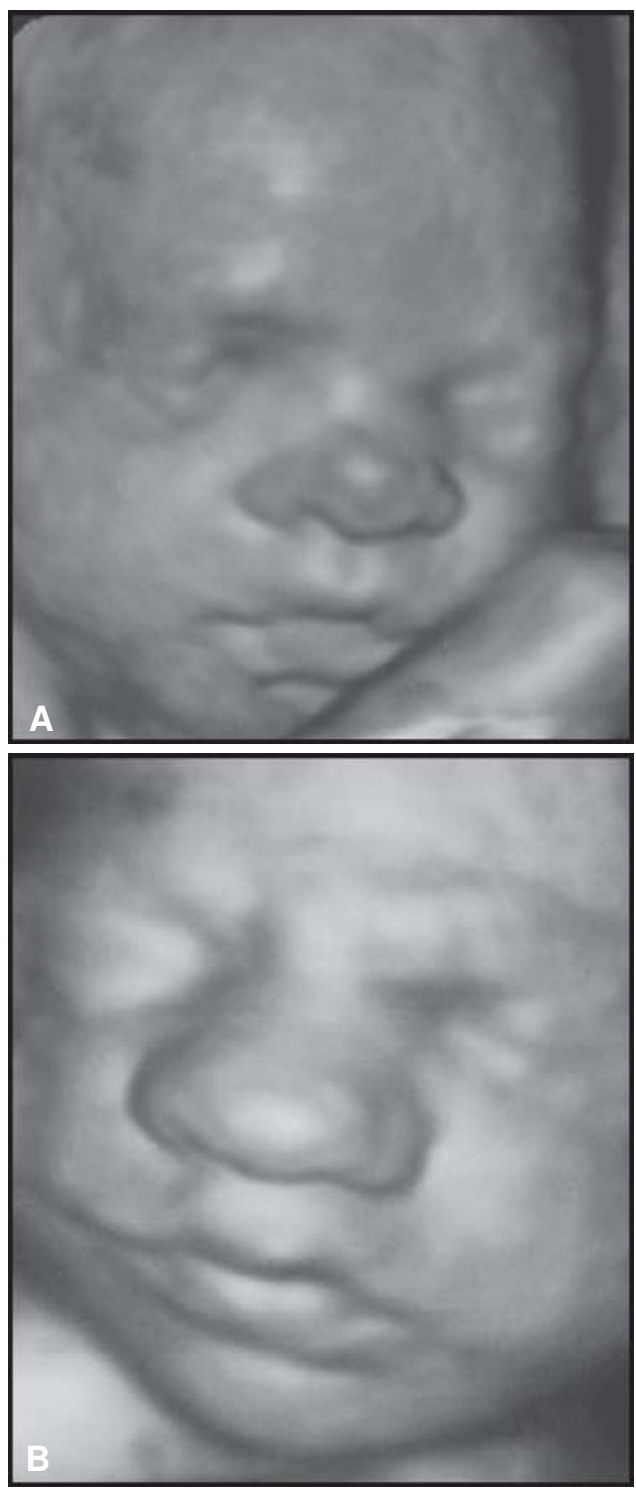

Fig. 4: Fetal face expressing emotions (speculates that these are sad babies)

increasing gestational age. ${ }^{53}$ In the longitudinal study, standard parameters of fetal movements and facial expressions in all trimesters of pregnancy were obtained and published. ${ }^{53}$ Some illustrative examples of that work are presented in Figures 6 to 9. In first trimester, a tendency toward increased frequency of fetal movement patterns with increasing gestational age was noticed (Fig. 6). At the beginning of the second trimester, the fetuses began to display a tendency toward increased frequency of observed fetal facial expression to the end of second trimester. An oscillation and dispersion of the incidence of all facial expressions was observed, as seen in the polynomial regression diagram for yawning (Fig. 7). All types of facial expression patterns display the peak frequency at the end of second
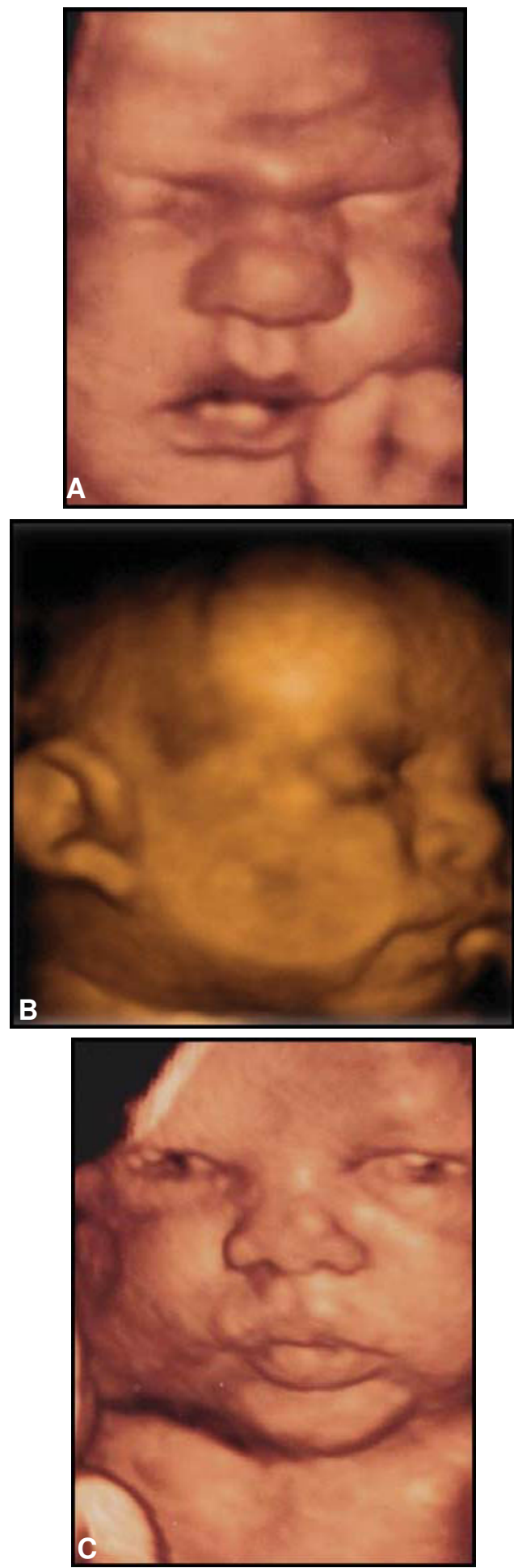

Fig. 5: Fetal face expressing mouthing (A), grimacing $(B)$ and eyelid movements $(C)$

trimester, except in isolated eye blinking which began to increase at the beginning of 24 weeks of gestation because the fetuses cannot open the eyelids before this period. During the third 
Table 4: Movements analyzed in embryos and fetuses in the first trimester ${ }^{53}$

- General movements

- Startle

- Stretching

- Isolated arm movements

- Isolated leg movements

- Head retroflexion

- Head rotation

- Head anteflexion

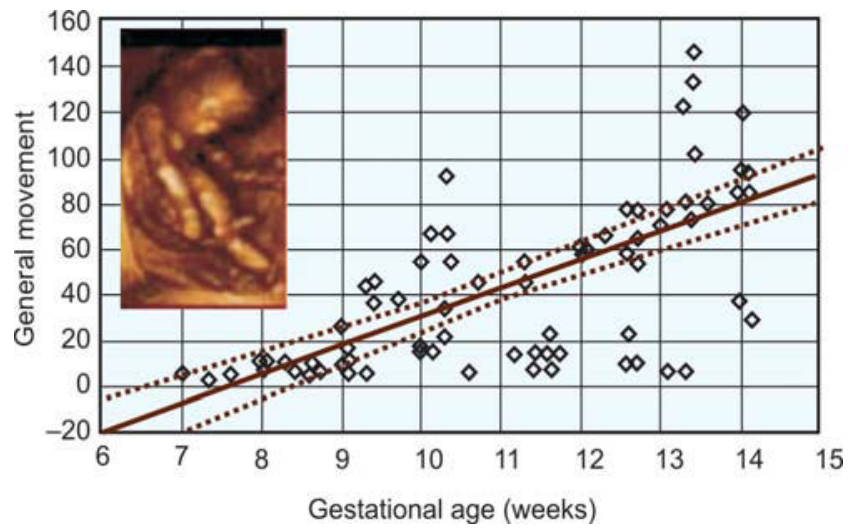

Fig. 6: The scatter plot and multiple regression analysis of the first trimester frequency of general movements versus the gestational weeks in the formula generating group

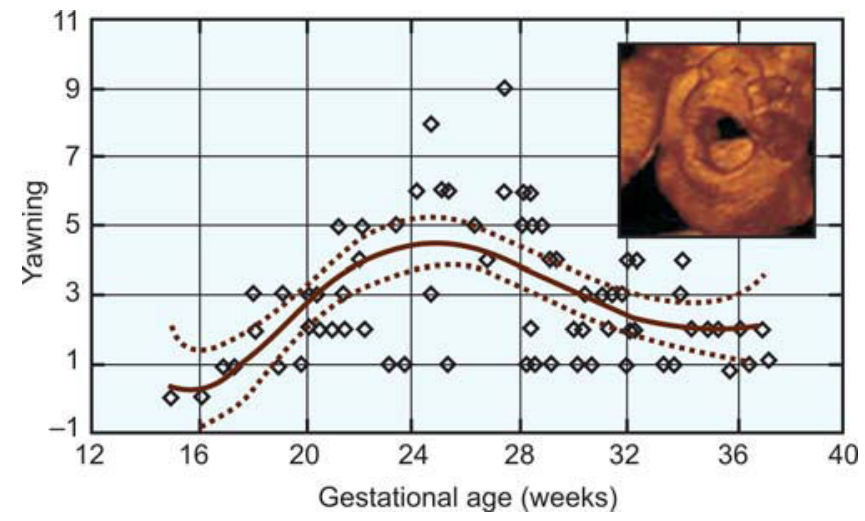

Fig. 7: The scatter plot and multiple regression analysis of the second and third trimesters frequency of yawning versus the gestational weeks in the formula generating group

trimester, the fetuses began to display decreasing incidence of fetal facial expressions. All types of head movements and hand to body contact, as well as hand movements indicate a tendency to decrease in frequency from the beginning of the second trimester to the end of third trimester (Figs 8 and 9).
Table 5: Movements analyzed in fetuses in the second and the third trimesters ${ }^{53}$

\begin{tabular}{ll}
\hline Facial expression & Hand and head movements \\
\hline - Isolated eye blinking & - Head retroflexion \\
- Mouthing & - Head rotation \\
- Yawning & - Head anteflexion \\
- Tongue expulsion & - Hand to head direction \\
- Srimacing & - Hand to eye direction \\
& - Hand to mouth direction \\
& - Hand to face direction \\
\hline
\end{tabular}

Table 6: Definition of some fetal movement patterns and facial expressions ${ }^{25,52}$

General movements : Series of movements with variable speed and amplitude, involve all parts of the body without distinctive patterning of body parts can be seen. Duration varies from a few seconds to about a minute

Startle

Quick generalized movements, starting in the limbs and spreading to the neck andtrunk, only last about one second

Stretching

A complex motor pattern, always carried out at a slow speed and consists of the forceful extension of the back, retroflexion of head, and external rotation and elevation of the arms

Isolated arm or legmovements

Rapid or slow movements, and may involve extension, flexion, external and internal rotation, or abduction and adduction of an extremity, without movements in other body parts

Head retroflexion, : Isolated retroflexions, rotations and anteflexions rotation and anteflexion of the head not associated with general movements. Usually carried out slowly, but they can also be fast and jerky

Hand to body contact: In this pattern of movement, the hand slowly (head, mouth, eye, face, ear) touches the body parts, with extension and flexion of the fingers

Grimacing The wrinkling of the brows or face in frowing

Isolated eye blinking: A reflex that closes and opens the eyes rapidly. Brief closing of the eyelids by involuntary normal periodic closing, as a protective measure, or by voluntary action

Yawning

Prolonged wide opening of the jaws followed by quick closure, with retroflexion of the head and elevation of the arms. This movement pattern is non-repetitive

Tongue expulsion : Facial expression characterized by expulsion of the tongue

Swallowing

Indicating that the fetus is drinking amniotic fluid. Swallowing consists of displacements of tongue and/or larynx

Mouthing

A facial expression characterized by mouth manipulation to investigate an object. Mouthing is most common in fetus and it may develop into a persistent, stereotyped behavior pattern. 


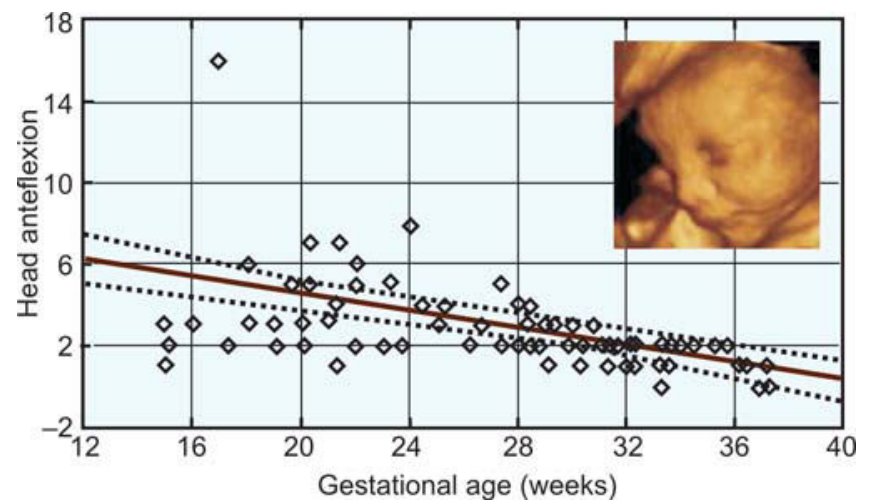

Fig. 8: The scatter plot and multiple regression analysis of the second and third trimesters frequency of head anteflexion versus the gestational weeks in the formula generating group

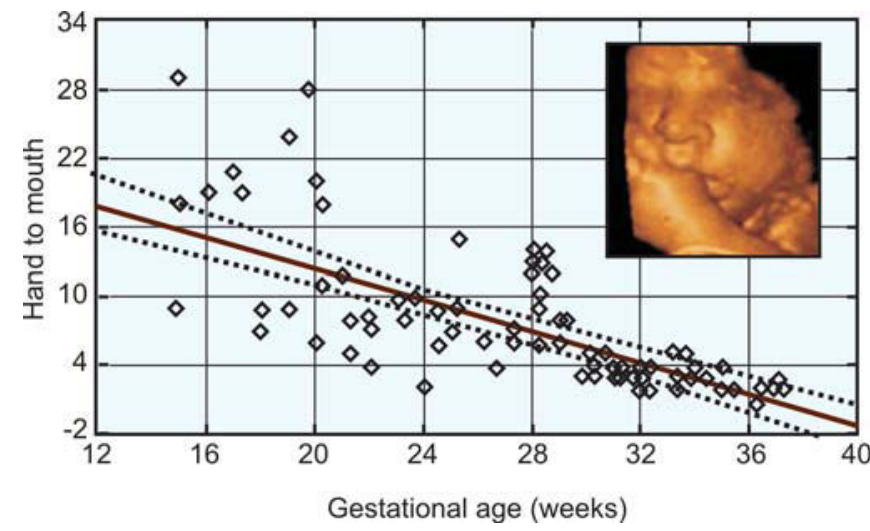

Fig. 9: The scatter plot and multiple regression analysis of the second and third trimesters frequency of hand to mouth movements versus the gestational weeks in the formula generating group

\section{Quality of GMs Studied by 4D Ultrasound}

As it was shown in postnatal studies of GMs, it is very important, besides the quantity, to study the quality of GMs as well. ${ }^{19,20}$ From the postnatal studies we have learned that changes in the quality of movements are much more predictable for disability than their quantity. ${ }^{19,20,55-58}$ There are still technical limitations of 4D equipment to assess quality of GMs, although the frame rate of 4D equipment is constantly improving.

\section{Continuity of GMs from Prenatal to Postnatal Life}

Postnatal studies of neonatal behavior have taught us that the assessment of behavior is a better predictor of neurodevelopment disability than neurological examinations. ${ }^{55} \mathrm{It}$ is important to mention that postnatal observation of movement patterns was introduced by Prechtl and coworkers in the way that they have been observing spontaneous movements of the infant using video typing and "off-line" analysis of both quantity and quality of the movement. ${ }^{56,57}$ They proved that assessment of general movements in high-risk newborns has significantly higher predictive value for later neurological development than neurological examination. ${ }^{55,58,59}$ Kurjak and coworkers conducted a study by 4D ultrasonography and confirmed earlier findings made by $2 \mathrm{D}$ ultrasonography, that there is behavioral pattern continuity from prenatal to postnatal life. ${ }^{50}$ Assessment of neonatal behavior is a better method for early detection of cerebral palsy than neurological examination alone. ${ }^{60} \mathrm{It}$ is being speculated that intrauterine detection of encephalopathy would improve the outcome. Although many fetal behavioral studies have been conducted, it is still questionable whether the assessment of continuity from fetal to neonatal behavior could improve our ability of early detection of brain pathology. Early detection could possibly rise an opportunity to intervene and even prevent the expected damage.

\section{COULD SOME POSTNATAL SIGNS OF NEUROLOGICAL DISABILITY BE USED PRENATALLY?}

It has been proven by now that ultrasonography is a powerful tool in the assessment of fetal behavior. 4D sonography brought up to light visual observation of the fetus, particularly in two especially important domains: fetal finger movements and facial expressions. ${ }^{41,61,62}$ This new technology is not only a tool of fetal observation but also a very useful tool to evaluate the development of fetal CNS in normally developing fetuses and those at high-risk. A basic understanding of fetal neurology includes defining of motor pathways involved, chronology of their maturation and direction of myelination. ${ }^{62,63}$ This information helps clinician in better interpretation of fetal movements. The experience acquired with the Amiel-Tison's Neurological Assessment at Term (ATNAT) helps us in interpretation of fetal movements. ${ }^{64-66}$

The domain of fetal neurology is already too extensive, but the focus of interest is mainly second trimester, despite the fact that spontaneous fetal mobility emerges and has already become differentiated at a very early age. ${ }^{25}$ This means that we will take into a consideration period of pregnancy from 20 to 40 weeks of gestation, including the end of the neuronal migration and the post-migratory phase corresponding to the development of neocortex. $^{22,23}$

As it was already mentioned, CP describes a group of disorders of the development of movement and posture, causing activity limitations, which are attributed to nonprogressive disturbances occurring at the time of fetal brain development. ${ }^{1-4}$ Motor disorders which occur in patients with CP are often accompanied by disturbances of sensation, cognition, communication, perception, and/or behavior, and/or with seizure disorder. ${ }^{1-4}$ "Disturbances" is a term that refers to events or processes that in some way influence the expected pattern of 
brain maturation. ${ }^{66}$ Those events or processes are many, with consequences varying from very conspicuous to very subtle. It should be kept in mind what many neurologists emphasize, that morphology does not always correspond to neurological outcome ${ }^{64-68}$ The opposite view is the one from pediatricians and neurophysiologists, who are involved in long-term followup studies, and they are certainly not that optimistic. It would be wise to consider long run prognosis, for each specific type of fetal brain damage and make appropriate decisions for conservative management.

Hopes have been headed toward MR, but in many cases brain changes cannot be detected as early as the first year of life; for example, pathological gliosis which causes secondary hypomyelinisation. ${ }^{64,65}$

While examining the fetal head by $4 \mathrm{D}$, sonographer should examine bony structures and fetal cranial sutures; if they are folding over one another, it is considered to be a bed sign previously described by Amiel-Tison. ${ }^{64,65}$

The majority of pediatricians believe that the main obstacle for early prediction of $\mathrm{CP}$ based on a functional observation of the fetus such as visual observation by $4 \mathrm{D}$ sonography, is due to the "precompetent" stage of most of the motor behavior observed in utero. ${ }^{64,65}$ One of the possible signs detected could be high arched palate (Figs 10A and B), described by AmielTison, in clinical assessment of the infant nervous system. ${ }^{64,65}$ What was believed as undetectable became visible by $4 \mathrm{D}$. Recently, the 3D "reverse face technique" has been described. This technique overcomes shadowing the fetal face by rotating the frontal facial image through $180^{\circ}$ along the vertical axis, so that the palate, nasal cavity and orbits become visualized. ${ }^{67,69}$

Pooh and Ogura examined 65 normal fetuses by $3 \mathrm{D} / 4 \mathrm{D}$. The purpose of their study was to investigate the natural course of fetal hand and finger positioning. ${ }^{70}$ During 9 th and on the beginning of 10th week, fetal hands were located in front of the chest and no movements of wrists and fingers were visualized. From the middle of 10th week, active arm movements were observed. ${ }^{70}$ This study is very important because it is showing that finger and thumbs movements began in the early stage of human life, long before the maturation of the upper system. Therefore, this motor activity depends on the lower system and not before 30 to 32 weeks switches to the upper control.

Amiel-Tison also described so called neurologic thumb squeezed in a fist (Figs 11A and B). Clenched fingers can also be detected by $4 \mathrm{D}$ sonography, as well as ovrlaping cerebral sutures (Figs 12A and B). ${ }^{41,70}$

Head anteflexion becomes visible during 10th and 11th gestational weeks, according to de Vries and co-workers. ${ }^{25}$ However, the activity of flexor muscles will depend on the upper system since 34 weeks of gestation. The absence of active head flexion explored by the raise-to-sit maneuver is one of the major neurological signs at 40 weeks of gestation..$^{18,65,66}$
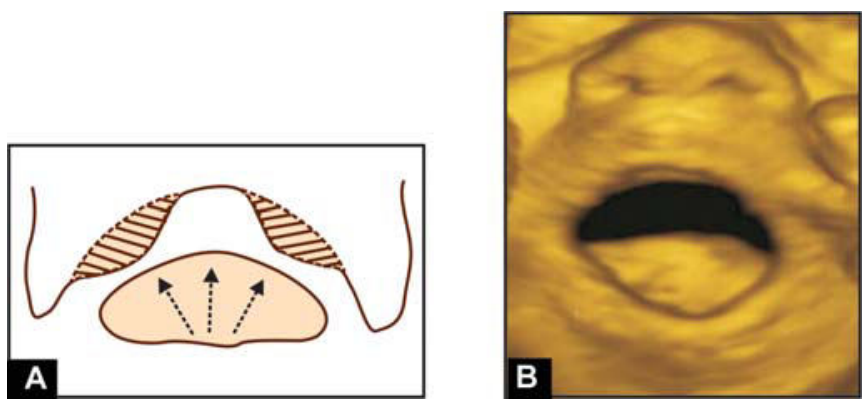

Figs 10A and B: High arched palate (A. Scheme, B. 4D ultrasonography $)^{64,65}$
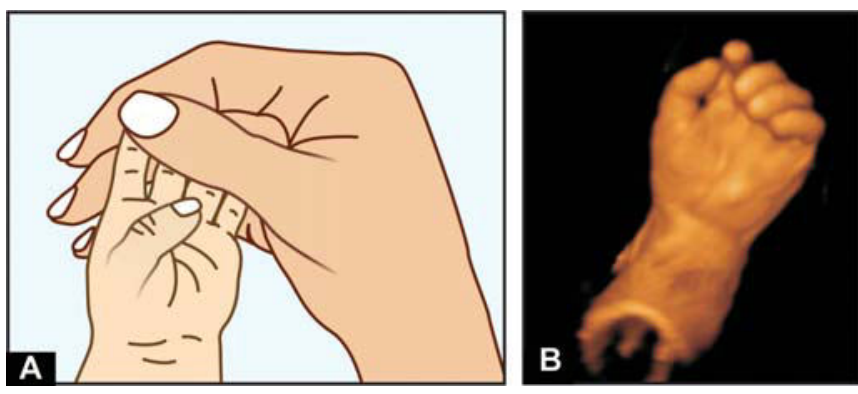

Figs 11A and B: Neurologic thumb squeezed in a fist (A. Scheme, B. Clenched fingers 4D USG) ${ }^{64,65}$

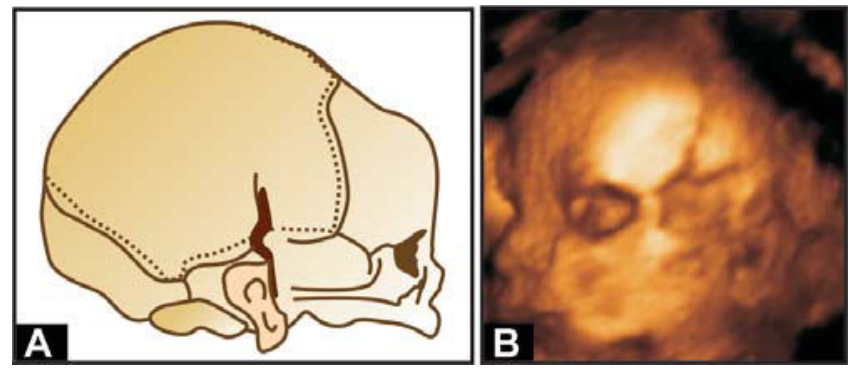

Figs 12A and B: Normal cranial sutures

(A. Scheme, B. Visualized prenatally by 4D USG pattern) ${ }^{64,65}$

\section{CONCLUSIONS}

Dipietro states that an emerging consensus recognizes the fact that "fetal neurobehavioral pattern reflects the developing nervous system"; however, we do not know yet the conceptual and methodological strengths and weaknesses of fetal assessments proposed. ${ }^{21} \mathrm{We}$ are not ready yet to predict the outcome inbetween two extreme situations, i.e. optimal or very abnormal. The predictive value for a favorable outcome of a complete neurobehavioral pattern in fetus as from 22 gestational weeks should be demonstrated. This is the goal of an on-going collaborative project by Kurjak et al.

Possibilities of 4D sonography are demonstrating the prenatal onset of a brain damage, based on morphological and 
functional signs. There is no doubt that this observation will be of enormous help, even though that prenatally observed signs are not yet highly predictive due to the brain immaturity, their identification will be at least recognized as a retrospective marker for a prenatal insult. ${ }^{64,65}$

Are we approaching the era when there will be applicable neurological test for fetus? This question is still not easy to answer, because even postnatally, there are several neurological methods of evaluation, while in utero we are dealing with more complicated situation and less mature brain. We have to publish proposal for fetal neurological test based on scoring of the quantity of GMs and some other signs. ${ }^{71}$ We believe that it will fulfill its main task which is to find out fetuses at high neurological risk, but we still have a long way to go.

\section{REFERENCES}

1. Mutch L, Alberman E, Hagberg B, Kodama K, Perat MV. Cerebral palsy epidemiology: where are we now and where are we going? Dev Med Child Neurol 1992;34:547-51.

2. Bax M, Goldstein M, Rosenbaum P, Leviton A, Paneth N, Dan B, Jacobsson B, Damiano D. Executive Committee for the Definition of Cerebral Palsy. Proposed definition and classification of cerebral palsy. Dev Med Child Neurol 2005;47:571-6.

3. Sankar C, Mundkur N. Cerebral palsy — definition, classification, etiology and early diagnosis. Indian J Pediatr 2005;72:865-8.

4. Shapiro BK. Cerebral palsy: a reconceptualization of the $\mathcal{C}^{\prime}$ spectrum. J Pediatr 2004;145(2Suppl):S3-7.

5. Rosen MG, Dickinson JC. The incidence of cerebral palsy. Am J Obstet Gynecol 1992;167:417-23.

6. Nelson K.B. Can we prevent cerebral palsy? N Engl J Med 2003;349:1765-9.

7. Clark SL, Hankins GDV. Temporal and demographic trends in cerebral palsy - fact and fiction. Am J Obstet Gynecol 2003;188:628-33.

8. Kuban KCK, Leviton A. Cerebral Palsy. N Engl J Med 1994;33:188-95.

9. Greenwood C, Newman S, Impey L, Johnson A. Cerebral palsy and clinical negligence litigation: a cohort study. BJOG 2003;110:6-11.

10. Badawi N, Kurinczuk JJ, Keogh JM, Alesandri LM, O'Sullivan $\mathrm{F}$, Burton PR, et al. Intrapartum risk factors for newborn encephalopathy: The Western Australian case-control study. BMJ 1998;317:1554-8.

11. Blumenthal I. Cerebral palsy-medicolegal aspects. J R Soc Med 2001;94:624-7.

12. MacLennan A. A template for defining a causal relation between acute intrapartum events and cerebral palsy: International consensus statement. BMJ 1999;319:1054-9.

13. Hankins GDV, Speer M. Defining the pathogenesis and pathophysiology of neonatal encephalopathy and cerebral palsy. Obstet Gynecol 2003;102:628-36.

14. Strijbis EMM, Oudman I, van Essen P, MacLennan AH. Cerebral palsy and application of the international criteria for acute intrapartum hypoxia. Obstet Gynecol 2006;107:1357-65.
15. Palmer FB.Strategies for the early diagnosis of cerebral palsy. $\mathrm{J}$ Pediatr 2004;145:S8-S11.

16. Walstab JE, Bell RJ, Reddihough DS, Brennecke SP, Bessell $\mathrm{CK}$, Beischer NA. Factors identified during the neonatal period associated with risk of cerebral palsy. Aust New Zeland J Obstet Gynaecol 2004;44:342-6.

17. Nelson KB,Ellenberg JH. Neonatal signs as predictors of cerebral palsy. Pediatrics 1979;64:225-32.

18. Gosselin J, Gahagan S, Amiel-Tison C. The Amiel-Tison neurological assessment at term: conceptual and methodological continuity in the course of follow-up. Ment Retard Dev Disabil Res Rev 2005;11:34-51.

19. Einspieler C, Prechtl HFR, Bos AF, Ferrari F, Cioni G. Prechtl's method on the qualitative assessment of general movements in preterm, term and young infants. Mac Keith Press: Cambridge, 2004.

20. Hadders-Algra M. General movements: a window for early identification of children at high risk for developmental disorders. J Pediatr 2004;145:S12-8.

21. DiPietro JA. Neurobehavioral assessment before birth. Ment Retard Dev Disabil Res Rev 2005;11:4-13.

22. Kostovic I, Judac' M, Petanjek Z, Šimiæ G. Ontogenesis of goal-directed behavior: anatomo-functional considerations. International J Psychophysiology 1995;19:85-102.

23. Kostovic' I, Seress L, Mrzljak L, Judaš M. Early onset of synapse formation in the human hippocampus: a correlation with NisslGolgi architectonics in 15- and 16.5-week-old fetuses. Neuroscience 1989;30:105-16.

24. Henderson-Smart DJ, Pettigrew AG, Edwards DA. Prenatal influences on the brainstem development of preterm infants. In Jones CT, Mott JC, Nathanielsz PW (Eds): Physiological Developments of the Fetus and Newborns. Oxford: Academic Press, 1985;pp 627.

25. de Vries JIP, Visser GHA, Prechtl HFR. Fetal motility in the first half of pregnancy. In Prechtl HFR (Ed): Continuity of neural functions from prenatal to postnatal life. Oxford, Blackwell. Clin Dev Med 1984;94:46-63.

26. Cioni G, Ferrari F, Einspieler C, Paoliceli PB, Barbani MT, Prechtl HFR. Comparison between observation of spontaneous movements and neurologic examination in preterm infants. J Pediatr 1997;130:704-11.

27. Jarvis S, Glinianaia SV, Torrioli MG, Platt MJ, Miceli M, Jouk PS, et al. Cerebral palsy and intrauterine growth in single births. European collaborative study. Lancet 2003;362:1106.

28. Reinold E. Identification and differentiation of fetal movements. Contrib Gynecol Obstet 1979;6:29-32.

29. Boue J, Vignal P, Aubrey JP, Aubrey MC, Aleese JM. Ultrasound movement patterns of fetuses with chromosomal anomalies. Prenat Diagn 1982;2:61-5.

30. Ferrari F, Prechtl HF, Cioni G, Roversi MF, Einspieler C, Gallo C. Posture, spontaneous movements, and behavioral state organisation in infants affected by brain malformations. Early Hum Dev 1997;50:87-113.

31. Kurjak A, Pooh RK, Merce LT, Carrera JM, Salihagic-Kadic A, Andonotopo W. Structural and functional early human development assessed by three-dimensional and four-dimensional sonography. Fertil Steril 2005;84:1285-99. 
32. Kurjak A, Carera JM, Medic M, Azumendi G, Andonotopo W, Stanojevic M. The antenatal development of fetal behavioral patterns assessed by four-dimensional sonography. J Matern Fetal Neonat Med 2005;17:401-16.

33. Andonotopo W. Morphological and dynamic assessment of fetal growth restriction by three-dimensional sonography. Doctor Thesis. Medical Scholl University of Zagreb, Zagreb, 2006.

34. Andonotopo W, Kurjak A, Ivancic-Kosuta M. Behaviour of anencephalic fetus studied by 4D sonography. J Matern Fetal Neonat Med 2005;17:165-8.

35. Einspieler C, Prechtl HFR. Prechtl's assessment of general movements. A diagnostic tool for the functional assessment of the young nervous system. MRDD Research Reviews 2005;11:61-7.

36. Allen MC. Developmental outcome and follow-up of the small for gestational age infant. Semin Perinatol 1984;8:123-56.

37. Campbell S. 4D, or not 4D: that is the question. Ultrasound Obstet Gyenecol 2002;19:1-4.

38. Brazelton TB. Neonatal Behavioural Assessment Scale (2nd edn). JB Lippincott: Philadelphia, 1984.

39. Jacobson B, Hagberg G, Hagberg B, Ladfors L, Niklasson A, Hagberg H. Cerebral palsy in preterm infants: a population based case-control study of antenatal and intrapartal risk factors. Acta Pediatr 2002;91:946-51.

40. Kurjak A, Vecek N, Hafner T, Bozek T, Funduk-Kurjak B, Ujevic B. Prenatal diagnosis: what does four-dimensional ultrasound add? J Perinat Med 2002;30:57-62.

41. Kurjak A, Azumendi G, Vecek N, et al. Fetal hand and facial expression in normal pregnancy studied by four-dimensional sonography. J Perinat Med 2003;31:496-508.

42. Azumendi G, Kurjak A. Three-dimensional and four-dimensional sonography in the study of the fetal face. Ultrasound Rev Obstet Gynecol 2003;3:160-9.

43. Kurjak A, Stanojevic M, Andonotopo W, Scazzocchio-Duenas E, Azumendi G, Carrera JM. Fetal behaviour assessed in all three trimesters of normal pregnancy by four-dimensional ultrasonography. Croat Med J 2005;46:772-80.

44. Andonotopo W, Medic M, Salihagic-Kadic A, Milenkovic D, Maiz N, Scazzocchio E. The assessment of embryonic and fetal neurodevelopment in early pregnancy: comparison between 2D and 4D sonographic scanning. J Perinat Med 2005;33:406-14.

45. Andonotopo W, Stanojevic M, Kurjak A, Azumendi G, Carrera JM. Assessment of fetal behavior and general movements by four-dimensional sonography. Ultrasound Rev Obstet Gynecol 2004;4:103-14.

46. Azumendi G, Kurjak A, Carrera JM, Andonotopo W, Scazzocchio E. 3D and 4D sonography in the evaluation of normal and abnormal fetal facial expression. In Carrera JM, Kurjak A (Eds): Atlas of Clinical Application of Ultrasound in Obstetrics and Gynecology. Jaypee Brothers Medical Publishers: New Delhi, 2006;pp250.

47. Azumendi G, Arenas JB, Andonotopo W, Kurjak A. Three dimensional sonoembriology. In Kurjak A, Arenas JB (Eds): Textbook of Transvaginal Sonography. Taylor \& Francis: London, 2005; pp 407.
48. Carrera JM. Fetal ultrasonography: the first 40 years. Ultrasound Rev Obstet Gynecol 2004;4:141-7.

49. Kurjak A, Carrera JM, Andonotopo W, Azumendi G, Medic M, Salihagic-Kadic A. Behavioral perinatology assessed by four dimensional sonography. In Kurjak A, Chervenak F (Eds): Textbook of Perinatal Medicine. Jaypee Brothers Medical Publishers: New Delhi, 2005;pp568.

50. Kurjak A, Stanojevic M, Andonotopo W, Salihagic-Kadic A, Azumendi G, Carrera JM. Behavioral pattern continuity from prenatal to postnatal life - a study by four-dimensional (4D) ultrasonography. J Perinat Med 2004:32:346-53.

51. Kurjak A, Stanojevic M, Azumendi G, Carrera JM. The potential of four-dimensional (4D) ultrasonography in the assessment of fetal awareness. J Perinat Med 2005;33:46-53.

52. Prechtl HFR. Ultrasound studies of human fetal behaviour. Early Hum Dev 1985;12:91-8.

53. Kurjak A, AndonotopoW, Hafner T, Salihagic Kadic A, Stanojevic M, Azumendi G, Ahmed B, Carrera JM, et al. Normal standards for fetal neurobehavioral developments - longitudinal quantification by four-dimensional sonography. J Perinat Med 2006;34:56-65.

54. de Vries JIP, Visser GHA, Prechtl HFR. The emergence of fetal behavior. II Quantitative aspects. Early Hum Dev 1985;12: 99120.

55. Seme-Ciglenecki P. Predictive value of assessment of general movements for neurological development of high- risk preterm infants: comparative study. Croat Med J 2003;44:721-7.

56. Einspieler C, Prechtl HF, Ferrari F, Cioni G, Bos AF. The qualitative assessment of general movements in preterm, term and young infants-review of the methodology. Early Hum Dev 1997;24:47-60.

57. Roodenburg PJ, Wladimiroff JW, van Es A, Prechtl HFR. Classification and quantitative aspects of fetal movements during the second half of pregnancy. Early Hum Dev 1991;25:19-35.

58. Cioni G, Prechtl HFR, Ferrari F, Paolicelli PB, Einspieler C, Roversi MF. Which better predicts later outcome in full term infants: quality of general movements or neurological examination? Early Hum Dev 1997;50:71-85.

59. Ferrari F, Cioni G, Einspieler C, Roversi MF, Bos AF, Paolicelli PB, Ranzi A, Prechtl HF.Cramped synchronized general movements in preterm infants as an early marker for cerebral palsy. Arch Pediatr Adolesc Med 2002;156:460-7.

60. Prechtl HFR. State of the art of a new functional assessment of the young nervous system. An early predictor of cerebral palsy. Early Hum Dev 1997;50:1-11.

61. Kurjak A, Jackson D (Eds). An atlas of Three- and Fourdimensional Sonography in Obstetrics and Gynecology. Taylor \& Francis Group: London, 2004.

62. Sarnat HB. Anatomic and physiologic correlates of neurologic development in prematurity. In Sarnat HB (Ed): Topics in Neonatal Neurology. New York: Grune and Stratton 1984; pp 1-24.

63. Sarnat HB. Functions of the corticospinal and corticobulbar tracts in the human newborns. J Pediatr Neurol 2003;1:3-8. 
64. Amiel-Tison C. Clinical assessment of the infant nervous system. In Levente MI, Chervenak FA, Whittle M (Eds): Fetal and Neonatal Neurology and Neurosurgery (3rd edn). Churchill Livingstone: London, 2001; pp 99-120.

65. Amiel-Tison C. Update of the Amiel-Tison neurologic assessment for the term neonate or at 40 weeks corrected age. Pediatr Neurol 2002;27:196-212.

66. Salisbury AL, Duncan Fallone M, Lester B. Neurobehavioral assessment from fetus to infant: the NICU network neurobehavioral scale and the fetal neurobehavioral coding system. MRDD Research Reviews 2005;11:14-20.

67. Pooh RK, Pooh K, Nakagawa Y, Nishida S, Ohno Y. Clinical application of three-dimensional ultrasound in fetal brain assessment. Croat Med J 2000;41:245-51.
68. Stanojevic M, Pooh RK, Kurjak A, Kos M. Three-dimensional ultrasound assessment of the fetal and neonatal brain. Ultrasound Rev Obstet Gynecol 2003;3:117-30.

69. Campbell S, Lees C, Moscoso G, Hall P. Ultrasound antenatal diagnosis of cleft palate by a new technique: the $3 \mathrm{D}$ "reverse face" view. Ultrasound Obstet Gynecol 2005;25:12-8.

70. Pooh RK, Ogura T. Normal and abnormal fetal hand positioning and movement in early pregnancy detected by three- and fourdimensional ultrasound. Ultrasound Rev Obstet Gynecol 2004;4:46-51.

71. Kurjak A, Stanojevic M, Andonotopo W, Marton I, Azumendi G. An attempt to produce neurological test for fetus based on 4D sonogrphy. J Matern Fetal Neonat Med 2007 (submitted for publication). 